\title{
Linkages between environmental issues and zoonotic diseases: with reference to COVID-19 pandemic
}

\author{
Jitendra Mishra ${ }^{1} \cdot$ Priya Mishra ${ }^{1} \cdot$ Naveen Kumar Arora $^{1}$ (1) \\ Received: 17 November 2020 / Revised: 28 February 2021 / Accepted: 2 March 2021 / Published online: 29 March 2021 \\ (c) Society for Environmental Sustainability 2021
}

\begin{abstract}
Coronavirus disease (COVID-19) caused by severe acute respiratory syndrome (SARS) coronavirus 2 (SARS-CoV-2) has taken mankind by surprise with various unprecedented impacts on human life around the globe. This zoonotic pandemic is proving to be the most destructive disease outbreaks since decades. The increasing human population and anthropogenic activities have impacted the environment and have direct linkages with the current and other recent outbreaks of zoonotic diseases. Despite having a difference in their origin, major reasons behind the emergence and spread of zoonotic pandemics are related to activities such as habitat fragmentation, deforestation, biodiversity loss, intensive agriculture and livestock farming, uncontrolled urbanization, pollution, climate change and bushmeat hunting and trading. It is important to focus on environmental and climatic factors that are involved in the emergence of such pandemics involving novel human pathogens and viruses in particular. Research and data analysis, particularly in relation to COVID-19, has shown that meteorological factors along with population density and living conditions (particularly in the urban and semi-urban areas) play a crucial role in the intensity, evolution and spread of SARS-CoV-2. This particular virus is novel but coronaviruses have a long history and are known to cause disease outbreaks earlier as well. COVID-19 pandemic provides learning for the future, in particular the importance of environmental sustainability for controlling such outbreaks. A strategic plan can be developed involving policy-makers, organizations, and governments to control the onset and spread of the novel pathogens. This review-based study recommends that prevention of COVID-19 like pandemics from re-occurring is through tackling the issues related to the environment by controlling anthropogenic activities. It will also be important to track the lineage and future evolution course of such human pathogens so as to determine the nexus of environmental and biological factors in the development and spread of novel strains.
\end{abstract}

Keywords COVID-19 $\cdot$ Pandemic $\cdot$ Zoonoses $\cdot$ Environment $\cdot$ Climate change $\cdot$ Anthropogenic

\section{Introduction}

Large-scale outbreaks of infectious diseases, also known as pandemics, have caused significant loss of human life along with economic and social issues. There have been several zoonotic pandemic outbreaks which have caused morbidity and mortality over a wide geographical region since recorded history (Fig. 1). Apart from direct impact on human life, these highly contagious zoonoses influence socio-economic activities such as education, employment,

Naveen Kumar Arora

nkarora.bbau@gmail.com

1 Department of Environmental Science, School for Earth and Environmental Sciences, Babasaheb Bhimrao Ambedkar (Central) University, Lucknow 226025, India transportation, tourism, trade and health care system (Cascio et al. 2011; Torgerson and Macpherson 2011; Epp and Waldner 2012; Smith et al. 2019). Currently, the whole world is affected due to a novel zoonotic disease known as coronavirus disease (COVID-19). COVID-19 was first spotted in December 2019 in Wuhan, Hubei province of China, when dozens of people were hospitalized due to pneumonia-like symptoms with unknown causes (Zhu et al. 2020). Later, preliminary tests and epidemiological studies indicated that COVID -19 was caused by a new zoonotic coronavirus strain named as "severe acute respiratory syndrome (SARS) coronavirus 2" (SARS-CoV-2) by the International Committee on Taxonomy of Viruses (ICTV) (Wu et al. 2020a). SARS$\mathrm{CoV}-2$ showed genetic similarities with earlier reported highly pathogenic coronaviruses such as "severe acute respiratory syndrome coronavirus" (SARS-CoV) and the 


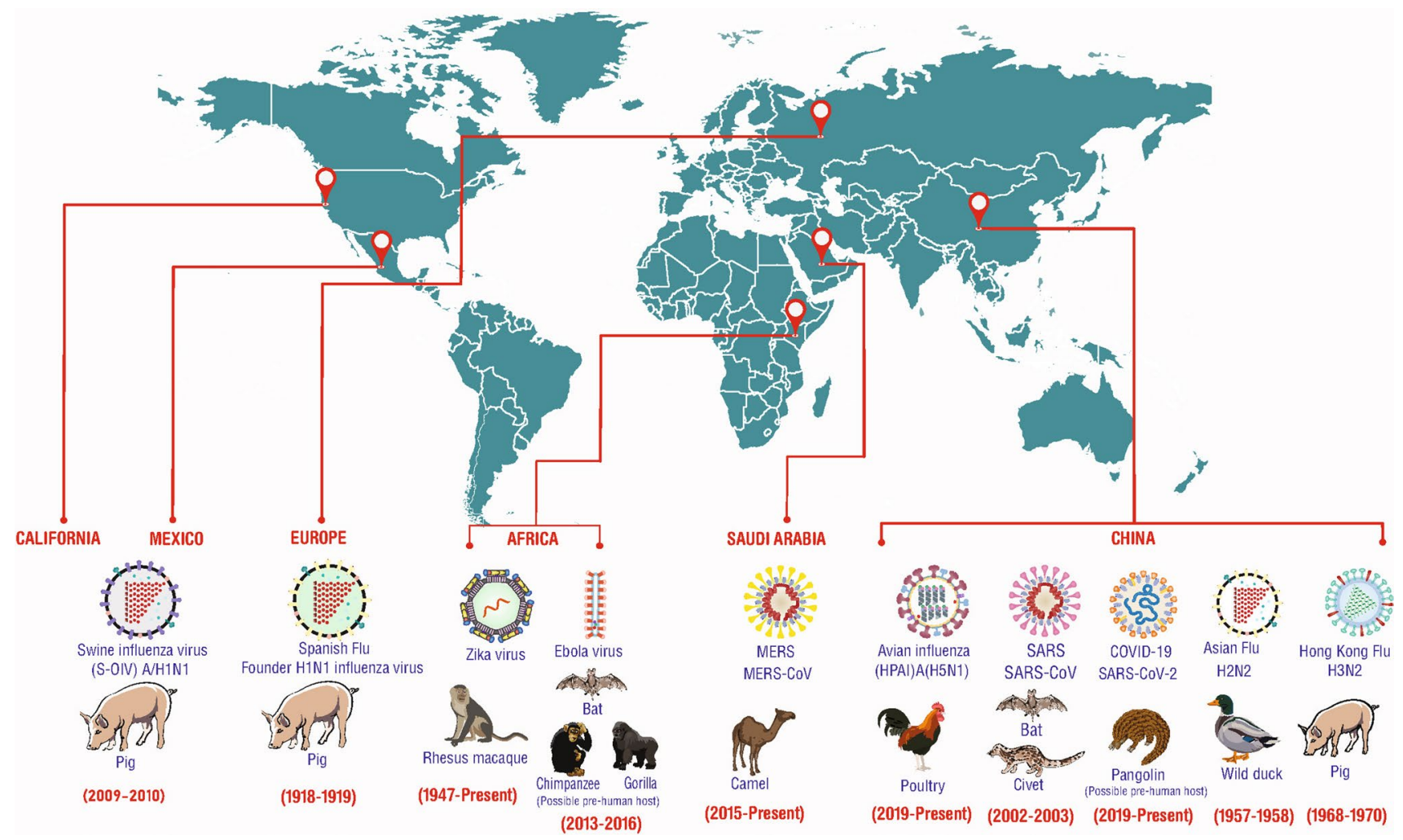

Fig. 1 Major zoonotic pandemic outbreaks in the recorded history

"Middle East Respiratory Syndrome Coronavirus" (MERS$\mathrm{CoV}$ ) causing acute respiratory distress syndrome (ARDS) in humans (Zhou et al. 2020; Kong et al. 2020). Initial COVID-19 patients are supposed to be related to a seafood market in Wuhan known for selling of fresh seafood, and on-site slaughter of wild animals. It was reported that a wild animal could be a pre-human host of SARS-CoV-2. Earlier investigations have already confirmed that wild animals such as horseshoe bats and civets may act as the natural and intermediate hosts to coronaviruses that are phylogenetically related to SARS-CoV (Cui et al. 2019). Recent evidences prove the potential of pangolins as the zoonotic reservoir of SARS-CoV-2-like coronaviruses (Xiao et al. 2020). However, the phylogenetic approaches suggest that the origin time of the virus can be as early as first half of September 2019 (Doğan et al. 2020). There had been some assumptions that virus may have escaped from a laboratory, probably the Wuhan Institute of Virology (WIV), Wuhan, which is known for research on coronaviruses and also known for isolation and collection of coronaviruses from bat samples ever since the original SARS outbreak of 2002-2003 (Hu et al. 2017; Cyranoski 2020). Not only WIV, Wuhan Centers for Disease Prevention and Control (WCDPC) which is near to the Huanan market and known for housing many bats carrying coronaviruses may probably be possible route for the lab escape of the virus. ${ }^{1}$ On the other hand, some notable genomic features (binding to the human receptor ACE2; and structure of the spike protein) suggest that most likely the virus evolved from related SARS-CoV-like coronavirus and transmitted through a natural process (Anderson et al. 2020).

Scientific data and research have pointed that the frequent emergence of novel zoonotic diseases has deep linkages to the changing global environment (EstradaPeña et al. 2014). Destruction of natural habitats of wild animals, possible reservoirs of novel human pathogens, and an increase in man-animal conflicts is being directly related to the emergence of such pandemics. In one of its report, Food and Agricultural Organization (FAO) mentioned that more than $70 \%$ of human diseases are of animal origin, and have a direct relation with humans' reliance on animals for food (FAO 2013). However, other key reasons related to the emergence and transmission of novel zoonotic pathogens to humans include fragmentation of natural ecosystems (Salkeld et al. 2013; Estrada-Peña et al. 2014; Allen et al. 2017; Schmeller et al. 2020), global warming and climate change (Zell et al. 2008; Revich et al. 2012; Carlson et al. 2020), pollution (Chaber 2018), intensive livestock cultivation, and unsustainable and

\footnotetext{
$\overline{1}$ https://project-evidence.github.io/.
} 


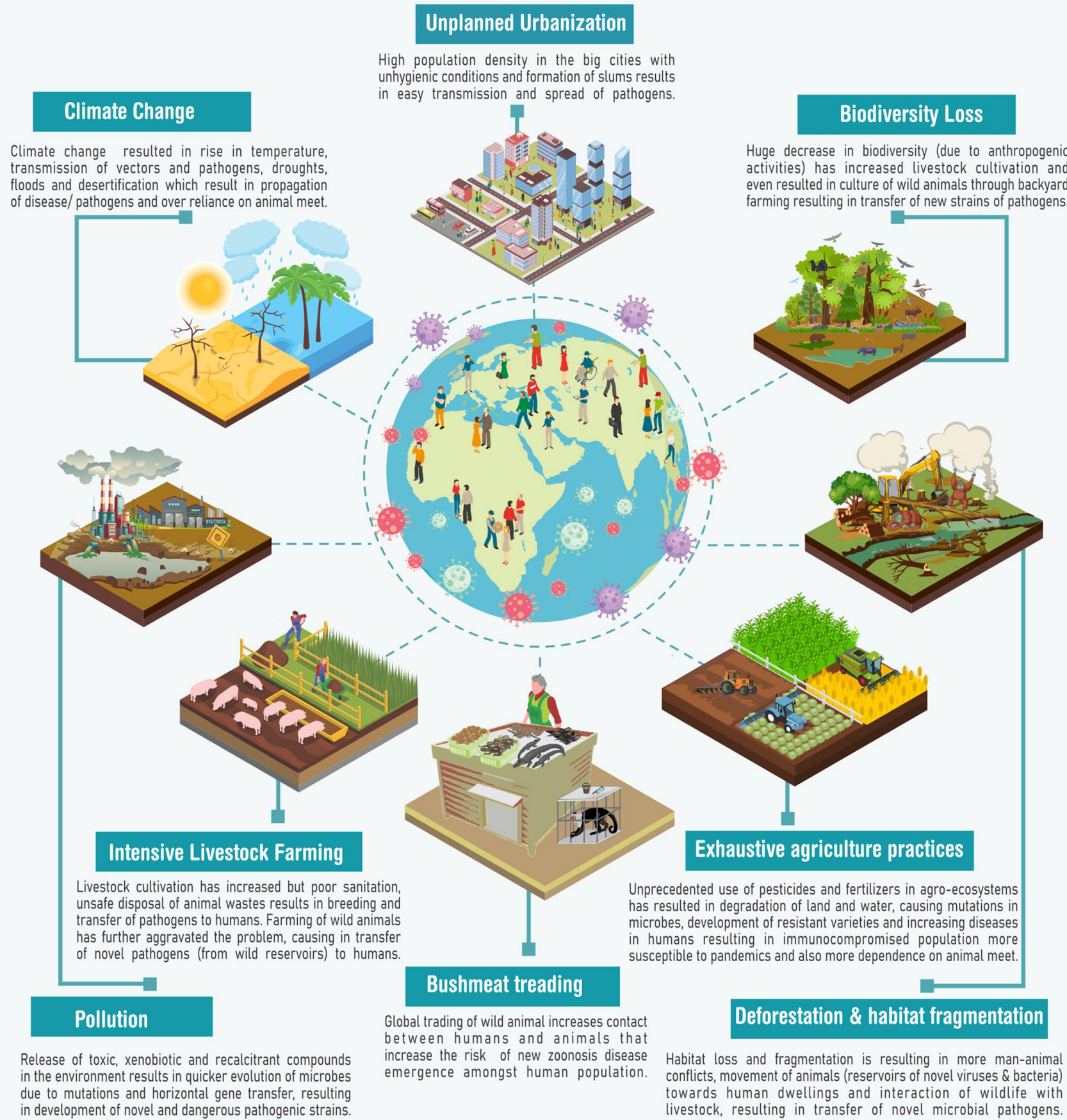

Fig. 2 Environmental issues that lead to the pandemic

aggressive chemical-based agriculture (Jones et al. 2013; Smit and Heederik 2017) (Fig. 2). In this review, we have discussed the relevance of environmental factors by critically analyzing the already published reports and data in relation to the origin and spread of novel human pathogens/diseases including the COVID-19 pandemic. It is also explained that how there are commonalities between
COVID-19 and past zoonotic epidemics/ pandemics that have emerged due to changing environmental scenario, largely due to anthropogenic activities. Additionally, recommendations are also proposed to sensitize policy-makers, leaders, and the public for realizing the importance of environment linkages in managing and controlling the onset and spread of such pandemics in the future. 


\section{Environmental issues and the emergence of pandemics}

In 2016, about four years before the outbreak of the COVID-19 pandemic, the United Nations Environment Programme (UNEP) warned that the frequent emergence of zoonotic diseases at the global level could pose a severe health risk to humans (UNEP 2016). It was also pointed out that most of the emerging infectious diseases in humans are zoonotic and interlinked with the drastic change in climatic and environmental conditions (UNEP 2016). Climatic and environmental changes have accelerated the rate of emergence of zoonotic diseases across the globe (Sutherst 2004). In this section, how the environmental factors including anthropogenic activities are becoming important in relation to the emergence and spread of novel pathogens and pandemics is discussed.

\section{Climatic conditions}

There have been many studies in the past that have shown a correlation of previous pandemics with climatic factors and the environment. For instance, in tropics change in climatic conditions have led to the intensive spread of the carriers and vectors of zoonotic viruses which increased the transition of viruses from their carrier to the animal host (Armon and Cheruti 2012). Studies have also indicated that climate-driven changes such as temperature and precipitation may bring genetic instability in the evolutionary structure of viruses as noticed in the West Nile virus (WNV) in North America where temperature caused an adaptive mutation to efficiently propagate virus at elevated temperatures (Brault 2009). While studying MERS-CoV, it was found that about $56.1 \%$ of the positive cases aroused between April to August, and the viability of the virus was favored by high temperature, high ultraviolet index, low wind speed, and low relative humidity (Altamimi and Ahmed 2019).

In the case of COVID-19, studies on the effects of temperature, and relative humidity on disease incidence and spread remain to be contradictory or inconclusive, with data showing positive as well as negative relation (Prata et al. 2020; Sobral et al. 2020) or in some researches no relationship at all (Yao et al. 2020). Wu et al. (2020b) analyzed the effect of meteorological conditions (temperature and humidity) on new cases and deaths due to COVID19. By using a log-linear generalized additive model (GAM) they showed that temperature and humidity were inversely correlated with daily new cases and deaths due to COVID-19. It was suggested through GAM that every

$1{ }^{\circ} \mathrm{C}$ rise in temperature resulted in a $3.08 \%$ reduction in daily new cases and a $1.19 \%$ reduction in new deaths and every $1 \%$ increase in humidity reduced daily new cases and deaths by $0.85 \%$ and $0.51 \%$ respectively. Through a modified susceptible-exposed-infectious-recovered (M-SEIR) model which is a type of compartmental model used for the mathematical modeling of infectious disease transmission, Shi et al. (2020) confirmed that COVID-19 transmission rate decreased with the increase of temperature. In the same study, distributed lag nonlinear models confirmed no significant association between COVID-19 incidence and absolute humidity.

Increase in global temperature in the past few decades and future projections (of around $3{ }^{\circ} \mathrm{C}$ rise by 2050) (IPCC 2013) have and will result in the transfer of vectors (like insects) of human pathogens and reservoirs (as well) in unreported regions of the world (Caminade et al. 2019). Many of the emerging zoonoses have been related to viruses and transmitted by arthropods (vectors) and reservoir animals (Wang and Crameri 2014). Hence the effect of climate factors, particularly with a global increase in temperature, can provide much more information on disease ecology of zoonotic agents and their spillover to humans. It will be important to understand the effect of climate change (increase in global temperature) on host-vector systems.

The influence of climate warming and the risk of the spread of infectious diseases in Arctic regions has been studied by some workers (Kutz et al. 2009; Parkinson et al. 2014; Waits et al. 2018). These studies show that both microbial disease agents and vector species will proliferate due to warming in colder regions. Rising temperatures will affect ecosystems more profoundly in the polar regions resulting in a shift of density and distribution of animal reservoirs and arthropod vectors (Parkinson et al. 2014). The mean temperature is increasing resulting in more warmer days in the cooler regions of the globe, facilitating the spread of vectors, migratory animals, and birds leading to the transmission of pathogenic viruses. This allows reservoir species to survive for a longer time and expanding their habitat range that will increase the high transmission of zoonotic bacterial and viral pathogens to humans in locations nearer to poles (Parkinson et al. 2014). Climate change can impact the non-human reservoirs by altering the ecosystems directly or indirectly resulting in better conditions or the reverse, due to change in precipitation patterns, temperature, humidity and so on. Vectors or reservoirs can be dispersed through trade, migration, or along with humans, establishing pathogens in new pockets where climate change may have already resulted in conducive conditions. Spread of dengue virus in southern Europe is a classic example (Rocklöv and Dubrow 2020).

Prediction of climatic conditions in advance can help in forecasting the emergence and propagation of pathogenic viruses and bacteria or their vectors. Harris et al. (2019) showed that climate conditions i.e. relative humidity, 
temperature, and the population are the key determinants related to the occurrence of an endemic in a particular geographical region. As far as the influenza epidemic is concerned, it has also been found that the spread of disease from one continent to another is linked with climate-driven changes. For example, in the case of H5N1 transmission, it was found that climatic factors such as temperature, relative humidity, and wind speed changed the migration patterns in migratory birds which increased avian flu outbreaks in some regions in Egypt (Naguib et al. 2019). The increasing global temperature and associated events such as rainfall/humidity and droughts have to be taken into consideration to predict the possible spread of microbial pathogens, their vectors or reservoirs along with the conducive conditions.

Over the past few decades, ecological niche modeling (ENM) approaches are also used to forecast the emergence of pandemic outbreaks. The ENM based studies have suggested that fluctuations in micro-climatic conditions and ecosystem destruction including habitat loss are among the essential environmental parameters related to the emergence of novel zoonoses (Carlson et al. 2016; Nyakarahuka et al. 2017). The model was found to be practically useful in gathering information on the transmission of EBOLA virus, hemorrhagic fever (HF), and Zika virus in Central and Western Africa (Peterson et al. 2004). While in the case of the current outbreak of SARS-CoV-2, an ENM based study by Araújo and Naimi (2020) predicted that temperate, warm, and cold climates are more favorable for the spread of the virus compared to tropical climates. However, the model has also shown uncertainties in the spread of the disease across sub-Saharan Africa, Latin America and Southeast Asia. Conceptual and methodological deficiencies in the study were challenged by Chipperfield et al. (2020). They claimed that species distribution models (SDMs) to predict the suitability of the climate for the spread of SARS-CoV-2 over the coming months were not appropriately used and also application guidelines of SDMs did not meet the international standards. On the other hand, Gupta et al. (2020) concluded that although no single meteorological attribute can clearly explain the spread of SARS-CoV-2, in tropical and subtropical regions of India, however, hot and arid areas with low altitude are most affected by COVID-19. Ma et al. (2020) reported that diurnal temperature and humidity play a crucial role in the number of deaths due to COVID19. Some other theories have also emerged predicting that COVID-19 will follow a seasonal pattern similar to other respiratory viruses SARS and MERS (Sajadi et al. 2020; Sanchez-Lorenzo et al. 2020). However, these are yet to be tested and confirmed practically. Although, it is not going to be as easy to predict the climatic impact without involving variables affecting the mobility of pathogens, or their animal reservoirs because of the involvement of multitude of factors such as socio-economic, development, urbanization, population density, levels of greenhouse gas emissions, air pollution and travel.

\section{Extreme weather and climatic conditions}

Climatic extremes such as extensive floods and droughts have proven as an apparent cause for the spread of pandemics. As per United Nations Convention to Combat Desertification (UNCCD), natural disasters such as droughts and floods have drastically increased in the past fifty years and this is mainly attributed to climate change and global warming (UNCCD and FAO 2020). Desertification of land has increased in the past few decades and if the emission of greenhouse gases (GHGs) continues as it is, this will increase the pace of conversion of fertile land to marginal and arid, with low productivity (Arora 2019). Earlier, Shaman et al. (2005) have found that widespread drought followed by wetting brought avian hosts and vector mosquitoes into Southern Florida. Similarly, Paull et al. (2017) had predicted that over the next 30 years, increased drought severity could upsurge by three times the cases of WNV in regions where humans have low immunity against the virus. Additionally, increasing droughts and desertification will result in enhanced dependence on bushmeat resulting in more chances of transmission of zoonotic pathogens to humans (da Silva Santos et al. 2019). The occurrence of floods, due to unpredictable and heavy rains has been indirectly linked with high incidences of vector-borne infectious disease. For instance, there were more outbreaks of Dengue viruses, WNV, and malaria due to heavy rainfall and flooding in Romania (1996-97), Czech Republic (1997), Italy (1998), southern Africa (2000), and some parts of Southeast Asia (2011) (Han et al.1999; Hubálek and Halouzka 1999; Kondo et al. 2002; Memon et al. 2014). Shaman et al. (2005) stated that a wide occurrence of drought and wetting can also increase the probability of infectious diseases. As far as COVID-19 is concerned occurrence of flood and drought events maximized compound climate risks and are likely to intersect with the pandemic crisis all around the world (Phillips et al. 2020). Natural disasters such as floods have resulted in an impact on dealing with the COVID-19 pandemic, due to interruption in health and other support systems (Guo et al. 2020). Floods can also result in the spread of communicable diseases because of the establishment of relief camps where population density is high, conditions can be unhygienic and there is a lack of proper nutrition or availability of potable water (Okaka and Odhiambo 2018). Forecasting and preparedness for extreme weather events such as floods, cyclones and droughts is very important to tackle the spread or containment of highly infectious diseases such as COVID-19. 


\section{Biodiversity loss}

Loss of biodiversity is closely associated with frequent emergence and transmission of zoonotic diseases (Keesing et al. 2010). Biodiversity loss makes an ecosystem more fragile and possible breach by the pathogens to humans becomes much easier. Changes in biodiversity may affect interactions between a host and a pathogen or with other species that act as reservoirs or vectors. COVID-19 is also a possible product of the devastation of global biodiversity resulting in unhealthy and even more fragile ecosystems. ${ }^{2}$ There have been some incidents where either an increase or decline in species richness potentially affected the risk of the emergence of infectious diseases both in plants and animals (Morand et al. 2014). Previously used modeling approaches to quantify the global emergence of infectious diseases (EID) indicate that high human population density and growth, latitude, rainfall, and wildlife diversity are also characteristics to identify geographical hot spots involved in the emergence of infectious diseases particularly those originating from wildlife (Allen et al. 2017). Sudden changes in species diversity can also result in an upsurge of novel pathogens. Nipah virus outbreak in Malaysia in the late 1990s is an ideal example where the fragmentation of batrich rainforests increased their population and brought them closer to pigs in local farms resulting in the transmission of the virus from bats to pigs to humans (Epstein et al. 2006). While, in hantavirus outbreaks, it was found that a decline in the diversity of small mammals' reservoir (rodent) increased the prevalence of viruses which amplified the risk of human transmission (Suzán et al. 2009).

Biodiversity loss is correlated with a decrease in forest cover, increased human-animal conflicts, upsurge in livestock farming, and cultivation of wild animals. In a study, Bloomfield et al. (2020) stated that deforestation and landscape fragmentation can increase the prevalence of novel zoonotic diseases. By using behavioral survey data and highresolution satellite imagery, they predicted that in the near future interactions between disease-carrying wild nonhuman primates (NHPs) and humans will become more common and lead to the emergence of new viruses. This study correlates with a recent finding that pangolin could have acted as disease-carrying NHP in transmitting SARS-Cov-2 in humans.

Fragmentation of habitats results in hindrance in the movement of migratory birds and animals. This along with hunting of migratory birds and animals (which can be reservoirs of novel human pathogens) can play an important role in the transmission of diseases (Crowl et al. 2008).

\footnotetext{
$\overline{2}$ https://en.unesco.org/events/covid-19-and-its-link-biodiversity-illeg al-wildlife-trafficking-and-bioculturality.
}

Migratory species are hunted and their meat is sold in many of the wet markets around the globe. Meat consumption of migratory animals and birds can be particularly dangerous as the exposure to new pathogens that they carry can increase disease severity many times more in immunologically weak persons or the indigenous populations. Hence, it is important to track the routes of migratory species from time to time through suitable techniques to ensure their movement and assess the emergence of new pathogens from these species.

The introduction of allochthonous species by humans or through their activities may also increase the probabilities of transferring a pathogenic strain into new locations that can become epicenter of zoonoses. Invasive alien species (IAS) can cause havoc to the indigenous species and bring novel diseases in wild animals (Roy et al. 2019), which can even get transmitted to humans. IAS can disturb the biodiversity of an ecosystem that can further aggravate the problem. It is very difficult to predict the spread of such alien pathogens in animal reservoirs or to humans making it more important to frame policies at the international level to control the spread of IAS.

\section{Anthropogenic factors}

Apart from changing climatic and environmental conditions, anthropogenic factors such as intensive livestock production, exhaustive agricultural practices, urbanization, globalization, and pollution have also proven to be important for the evolution and spread of zoonotic pathogens in the human population (Slingenbergh et al. 2004). For instance, intensification in livestock cultivation in the 'Eurasian ruminant street' and poultry production in Southeast Asia had led to an upsurge in highly pathogenic avian influenza in 2004 (Slingenbergh et al. 2004). In the case of Japanese encephalitis virus (JEV) outbreaks in Southeast Asia, increased production of irrigated rice and pig farming were reported as major anthropogenic factors to induce disease prevalence (van den Hurk et al. 2009).

In a systemic review, Jones et al. (2013) depicted the role of agricultural intensification and/or environmental changes in increasing the risk of zoonotic disease emergence. By analyzing the best available qualitative scientific evidence, they concluded that in the near future rate of zoonotic disease emergence or re-emergence will be closely linked to the evolution of the agriculture-environment nexus. The extensive use of agrochemicals in agriculture has resulted in the loss of biodiversity, an increase of desertification and marginal lands, and mutation among microbial populations in soil and water bodies (Arora 2018). It has been realized that pollution due to dangerous recalcitrant and xenobiotic pollutants including pesticides can be significant for the evolution of bacterial and viral pathogens and their transfer to humans. 
Apart from acquiring a new host range or crossing the host range barrier, a genetic mutation can transform a common pathogen into its deadliest form. The effect of pollution in creating novel mutant bacterial strains is well studied, however, in the case of animal viruses which also have a very high rate of mutation (Domingo and Perales 2014), heavy exposure of pollutant(s) may induce selective pressure to alter genomic structure, conferring protection against antiviral therapies. Many of the emerging contaminants (EC) are possible mutagens directly altering the genetic makeup of the microbes and can result in quick evolution (Petrie et al. 2015). Wild animals are also exposed to pollutants such as nonylphenol which can cause mutation in commensals and pathogenic microbes residing in them (VargasBerrones et al. 2020). Once microbes (bacteria or viruses) acquire the genes related to pathogenesis, either through evolution or horizontal gene transfer or mutation, they can be easily transferred from one species into another or from virus to virus or even bacteria to a virus, taking dangerous proportions. Horizontal gene transfer among microbes and co-evolution in viruses can be very catastrophic in the case of human pathogens and pollutants can be the spike to the process of natural evolution resulting in novel strains within no time. In terms of genetic makeup, SARS-CoV-2 showed $96.2 \%$ homology to a bat SARS-related coronavirus (SARSr-CoV; RaTG13) procured from Yunnan province, China; while similarity to the genome of the SARS-like virus is $85 \%$. Besides this, high conservation of $\mathrm{E}, \mathrm{M}$, and $\mathrm{A}$ structural proteins across all beta-CoV strains show genomic divergence (Wu et al. 2020c; Kaur et al. 2020). It will be important to keep track of the mutation rate of SARS-CoV-2, because RNA viruses are traditionally known for high mutation rates. Pachetti et al (2020) reported mutation hotspots in the SARS-CoV-2 genome and suggested that mutation in SARS-CoV-2 RNA dependent RNA polymerase (RdRp) can be very important in terms of resistance to anti-viral drugs such as polymerase inhibitors. These mutations in RdRp can be the smart strategy of the virus to escape the anti-viral drugs being used at present for COVID-19 treatment. This suggests the pace of evolution of SARS-CoV-2, although the exact reason for this is not known but role of environmental and ecological factors is proving to be very crucial.

\section{Urbanization and socioeconomic impacts}

Unplanned and unsustainable patterns of urban development have given rise to many emerging environment and health hazards (WHO 2009). Although there can be a variety of mechanisms through which urbanization affects the spread of pandemics but the common ones relate to high-population density, poor sanitation, poverty, living standards (particularly in slums), and behavioral or lifestyle changes that lead to a faster proliferation of infectious disease (Eubank et al.
2004). By using the census-calibrated model, Zachreson et al. (2018) showed that rapid urbanization affects peak timing, prevalence, and bimodality of influenza pandemics in Australia. COVID-19 has brought our focus on the environment of urban areas and slums in particular. It would not be wrong to mention that this pandemic has exposed the lack of urban planning around the globe and in developing countries in particular. Slums in the cities and peri-urban areas have become COVID hotspots in many countries and have become major areas for the spread of SARS-CoV-2 in big cities (Patel 2020). Lack of infrastructure and health facilities plus poor living standards aggravate the situation and make the inhabitants more vulnerable to epidemics and pandemics. The lockdowns in many countries forced migration of daily wagers and labourers to different regions. This not only resulted in more chances of acquiring COVID-19, but also its transmission in areas where there were no cases before. Apart from this, migrants suffered from poor health conditions, improper food availability and socio-economic hardships during the pandemic containment (Mukumbang et al. 2020). Oztig and Askin (2020) suggested a link between the scale of human mobility and the number of COVID-19 patients in countries where the magnitude of airline travel was high. They also found that countries that have higher population density and a greater percentage of the elderly population are found to be more likely to be affected with COVID-19 in comparison to other countries.

Díaz de León-Martínez et al. (2020) identified social, environmental and health risk factors in responding to the COVID-19 in the Mexican indigenous population. They found that, poor access to water, language barriers, and limited access to the internet are the major social factors curtailing relief measures against the disease. While addressing to environmental risk factors they found that indoor air pollution could aggravate the severity of COVID-19. Public health management system is easily overwhelmed in thickly populated urban centers, particularly beaming with unhygienic conditions, air and water pollution. Lack of coverage by health facilities in these areas and higher comorbidities such as respiratory tract infections, chronic pulmonary diseases, diabetes mellitus, hypertension, associated with urban life style are also identified to be responsible for high infection and death rate in urban centers around the globe (Ejaz et al. 2020).

Current research shows that transmission of respiratory droplets through human to human contact is the main infection source of SARS-CoV-2. Apart from this, asymptomatic cases (Gao et al. 2020) and fecal-oral transmission (Amirian 2020) are also reported to be involved in the transmission of COVID-19. It is recommended that countries around the world should take cautious steps to stop transmission and break the disease chains to save lives. Air pollution is another factor which is associated with big urban centers of 
the world. Wu et al. (2020d) concluded that a slight increase of $1 \mu \mathrm{g} / \mathrm{m}^{3}$ in $\mathrm{PM}_{2.5}$ can result in $8 \%$ increment in COVID19 death rate. If we see the data then it becomes clear that the cities with high air pollution levels are more affected with COVID-19 cases and deaths (Urrutia-Pereira et al. 2020). Dumping of waste material generated from the treatment centers/ hospitals (for COVID-19 patients) into the sewage and subsequently to water bodies could also raise the rate of COVID-19 transmission (Nabi et al. 2020). These contaminated sites could transmit the virus into flora and fauna and cause its re-emergence from sewage reservoirs and infected individuals, including sewage workers through direct contact or droplets (Nabi et al. 2020). This aspect of transmission through contaminated flora and fauna needs to be researched upon for SARS-CoV-2. However, overall, we need to relook at the unorganized development of urban centers and the conditions of the major part of the population living in these regions of the world.

\section{Bushmeat trade and consumption}

Over the past few years, trading and consumption of wild animal meat are also supposed to be involved in the emergence of new zoonoses. Bushmeat trading and consumption of exotic animal meat contribute an important chunk in the economy of several countries. Worldwide, Africa (Western, Southern, and Central region), Europe (Central and Eastern part), and Asia (East and Southeast regions) are extensively indulged in the trading of wild mammals, birds, and reptiles (Davies 2002; Bush et al. 2014; Sas-Rolfes et al. 2019; Scheffers et al. 2019). In the trading of wildlife meat, hygiene standards are often overlooked and humans directly come in contact with animal body fluids and tissues. The store or butcher houses are like incubators where new viral or bacterial species emerge and can get transmitted to humans (Armon and Cheruti 2012). Data indicates that every four months one new infectious disease emerges in humans and is likely to be linked to the consumption of NHP and other exotic animals (UNEP 2016). There are ample evidences indicating that the consumption of NHP is likely to be involved in the emergence of novel zoonotic diseases (Mossoun et al. 2017). For instance, human immunodeficiency virus (HIV 1 and 2) reached in humans by multiple cross-species transmission of simian immunodeficiency viruses (SIVs) through bushmeat hunting and trade (Sharp and Hahn 2011). In the case of earlier coronaviruses (causing epidemics), SARS-CoV is reported to be originated from bats then transmitted to humans, while MERS-CoV passed on from bats to camels to humans ( $\mathrm{Li}$ et al. 2020). As far as COVID-19 is concerned, the trading of pangolin for its culinary purposes and in traditional Chinese pharmacopeia is likely to be associated as an intermediate host responsible for virus transmission in humans (De Sadeleer and Godfroid 2020).

All these studies and data suggest that there are enough proofs and indications which imply that the anthropogenic activities have resulted in unprecedented damage to the environment and have acted as catalysts in the emergence of novel zoonoses and their transmission from animals to humans, as is the case of SARS-CoV-2.

\section{Recommendations for mitigating pandemics in the future}

COVID-19, although a pandemic of unprecedented nature, provides a chance to work on the possible causes of origin and transmission of deadly human pathogens. Since its emergence, several reports and suggestions have been presented by the researchers (Al-Shar'i 2020; Kumar et al. 2020; Podile and Basu 2020; Pan and Zhang 2020; Nabi et al. 2020; Wang et al. 2020). Population growth and anthropogenic activities have severely impacted the resilience of the ecosystems allowing pathogens such as SARS$\mathrm{CoV}-2$ to easily spread in the human population. A healthy ecosystem provides several layers of protection from the pathogens, which are getting breached due to a multitude of impacts as discussed in previous sections. Hence strategic advances in the direction of ecosystem restoration are of paramount importance (Everard et al. 2020). The collective role of environmentalists, ecologists, ethnobiologists, clinicians, epidemiologists and data analysts are important to learn from COVID-19 and implement the required measures for the prevention and spread of such pandemics in the future.

The spread or arrival of pathogens in different geographical regions can be reduced through quarantine and trade restrictions. Veterinarians and other wildlife specialists that are well trained in disease recognition and population medicine can play an important role in surveillance, control and prevention of emerging zoonoses (Chomel et al. 2007). For example, in an earlier study Barclay (2008) concluded that widespread transmission of HIV/AIDS could have been prevented if proper surveillance systems had been in place in the 1970s and 80s as the disease emerged. We should also take advantage of modern technology which has better use in reducing the risk of pandemics. According to Gonzalez et al. (2018), new technologies like computerized maintenance of geographical and historical datasets, geographic information systems (GIS), mathematical models, and molecular sequence data can better help in assessing the risk. Studies on the evolution of viruses and their cross-species transmission in epidemiological time scales are also very essential to predict the spread in novel hosts, vectors or reservoirs (Geoghegan and Holmes 2017). In relation to epidemiological investigations, genomic and molecular studies are very 
useful. For instance, through molecular sequences analysis, revelation of polybasic cleavage site, and the three adjacent predicted O-linked glycans that are unique to SARS-CoV-2 and were not previously reported in lineage $\mathrm{B}$ betacoronaviruses, have helped in prevention efforts to reduce SARSCoV-2 transmission in real-time (Andersen et al. 2020). It becomes very important to study the antigenic and molecular variations in the pathogenic microbial strains, particularly for RNA viruses such as SARS-CoV-2 which can mutate and create a problem for the development of vaccines and other treatment options (Abdullahi et al. 2020). Maurya et al. (2020) observed that mutations in SARS-CoV-2 can pose a challenge for development of vaccines that can target the diverse mutants of the virus, making continuous tracking very important. Islam et al. (2020) have reported that there are higher mutations in SARS-CoV-2 genomes and disease severity in the temperate regions in comparison to other parts of the world, suggesting some sort of relationship between meteorological factors and genetic variations in the novel coronavirus. They also suggested that it is important to study the conformational changes in proteins to identify the virulence, pathogenicity, and transmission of SARS$\mathrm{CoV}-2$. Assessing the mutational diversity and rate through molecular tools can be very important to track the behavior and spread of microbial pathogens in the future. This characterization of SARS-CoV-2 variants could lead to better therapeutic treatments, help in vaccine designing and aid in diagnostics approaches (Pachetti et al. 2020). Apart from gene sequence databases, it is also important to conserve different strains of the pathogens in physical form to study the lineages, evolutionary aspects and changes in pathogenicity related markers. There can be dedicated culture collection centers for pathogenic microbes including viruses. Use of technologies such as RT-PCR can help in the evaluation of viral load, which is correlated with disease severity, transmission and mortality. Viral load assessment can also help in determining the highly infected patients, helping in taking proper quarantine and isolation steps along with treatment strategies (Pujadas et al. 2020). Viral load also suggests about the infection stage, duration and timing for which a patient should be isolated. This can be very important to manage the pandemic and formulate the policies (Walsh et al. 2020).

In the current situation along with the health agencies and disease experts, local governments and international agencies should also come forward so as to tackle climate-related disasters along with pandemics such as COVID-19 (Phillips et al. 2020). Urban planning, movement of the population towards big cities and issues related to hygiene and health need to be taken up on priority. The concept of legal rights to nature for sustainable ecological governance through a societal framework can provide a more eco-centric and holistic approach to conserve the environment (Schoukens 2020). A paradigm shift is required in the thinking and working to let the nature breathe and sustain itself. This will also help in achieving the targets of Sustainable Development Goals. In fact, COVID-19 has given a chance to revitalize the health of the ecosystems, so as to correct the prevailing dichotomy between Man and Nature that is resulting in natural and biological disasters. Global initiatives and programs such as "One Health" by the World Organization of Animal Health, emphasized a correlation between human and animal health as an essential indicator of ecosystem health" "Surveillance Resource Center" for improving the practice of disease surveillance by the Center of Disease and Control and Prevention (CDC) $)^{4}$; Biosurveillance Resource Directory (BRD), ${ }^{5}$ an infectious disease database that includes diseases of biosurveillance relevance, "Global Virome Project" $(\mathrm{GVP})^{6}$ to discover unknown zoonotic viral threats and IUCN COVID19 resources $^{7}$ are helping to develop a multinational network for forecasting of upcoming pandemics. Biotechnological tools and study of the microbiome of possible reservoirs can also help in identifying the possible novel pathogens or their genes in advance. In future models can be developed by involving climatic conditions, climate change, deforestation levels, hygiene, availability of potable water and the presence of pollutants to indicate the possible hot spots from where the novel diseases can emerge. Conservation of natural resources, banning the trade of wildlife meat, reduction of GHGs emission and control of environmental pollution are important to restrict the emergence of novel pathogens and diseases.

\section{Conclusion}

Anthropogenic activities have impacted the integrity of the environment and are found to be associated with the emergence of novel diseases. Although there are differences among experts regarding the origin of SARS-Cov-2, the role of human indued environmental changes and climatic factors in the wide spread occurrence of zoonotic diseases and their spread cannot be ruled out. To protect the mankind from frequent arrival of epidemics or pandemics it is important to conserve the ecosystems. This will help in a multi-layered protection from novel zoonotic pathogens due to the healthy ecosystems and environment. Urban environment, health and regulations have to be maintained and eco-based policies need to be developed to prevent rampant outbreak of

\footnotetext{
${ }^{3}$ One Health. https://www.oie.int/en/for-the-media/onehealth/.

${ }^{4}$ https://www.cdc.gov/surveillancepractice/index.html.

${ }^{5}$ https://brd.bsvgateway.org.

${ }^{6}$ http://www.globalviromeproject.org/.

${ }^{7}$ https://www.iucn.org/resources/covid-19-resources.
} 
communicable diseases, as has happened with COVID-19. Additionally, more specific global environmental surveillance systems need to be developed to monitor emergence of novel zoonotic pathogens. The health ecosystem needs to be improved a lot for combating the pandemic situation. COVID-19 pandemic can be seen as a wake-up call for preparing us for future challenges and we must give attention to environmental issues that lead to such pandemics.

Acknowledgements The Fig. 2 has been designed using resources from Freepik.com.

\section{Declarations}

Conflict of interest The authors have declared no conflict of interest.

Compliance with ethics requirements This article does not contain any studies with human or animal subjects.

\section{References}

Abdullahi IN, Emeribe AU, Ajayi OA, Oderinde BS, Amadu DO, Osuji AI (2020) Implications of SARS-CoV-2 genetic diversity and mutations on pathogenicity of the COVID-19 and biomedical interventions. J Taibah Univ Med Sci 15:258-264

Allen T, Murray KA, Zambrana-Torrelio C, Morse SS, Rondinini C, Di Marco M, Breit N, Olival KJ, Daszak P (2017) Global hotspots and correlates of emerging zoonotic diseases. Nat Commun $8: 1-10$

Al-Shar'i NA (2020) Tackling COVID-19: identification of potential main protease inhibitors via structural analysis, virtual screening, molecular docking and MM-PBSA calculations. J Biomol Struct Dyn 1-16. https://doi.org/10.1080/07391102.2020.1800514

Altamimi A, Ahmed AE (2019) Climate factors and incidence of Middle East respiratory syndrome coronavirus. J Infect Public Health 13:704-708

Amirian ES (2020) Potential fecal transmission of SARS-CoV-2: current evidence and implications for public health. Int J Infect Dis 95:363-370

Andersen KG, Rambaut A, Lipkin WI, Holmes EC, Garry RF (2020) The proximal origin of SARS-CoV-2. Nat Med 26:450-452

Araujo MB, Naimi B (2020) Spread of SARS-CoV-2 Coronavirus likely to be constrained by climate. medRxiv. https://doi.org/10. $1101 / 2020031220034728$

Armon R, Cheruti U (2012) Environmental aspects of zoonotic diseases. IWA Publishing, London

Arora NK (2018) Agricultural sustainability and food security. Environ Sustain 1:217-219

Arora NK (2019) Impact of climate change on agriculture production and its sustainable solutions. Environ Sustain 2:95-96

Barclay E (2008) Predicting the next pandemic. Lancet 372:1025-1026

Bloomfield LSP, McIntosh TL, Lambin EF (2020) Habitat fragmentation, livelihood behaviors, and contact between people and nonhuman primates in Africa. Landsc Ecol 35:985-1000

Brault AC (2009) Changing patterns of West Nile virus transmission: altered vector competence and host susceptibility. Vet Res 40:43

Bush ER, Baker SE, Macdonald DWJCB (2014) Global trade in exotic pets 2006-2012. Conserv Biol 28:663-676

Caminade C, McIntyre KM, Jones AE (2019) Impact of recent and future climate change on vector-borne diseases. Ann N Y Acad Sci 1436(1):157-173
Carlson CJ, Dougherty ER, Getz W (2016) An ecological assessment of the pandemic threat of Zika virus. PLoS Negl Trop Dis 10:e004968

Carlson CJ, Albery GF, Merow C, Trisos CH, Zipfel CM, Eskew EA, Olival KJ, Ross N, Bansal S (2020) Climate change will drive novel cross-species viral transmission. bioRxiv. 202020012024918755

Cascio A, Bosilkovski M, Rodriguez-Morales AJ, Pappas G (2011) The socio-ecology of zoonotic infections. Clin Microbiol Infect 17:336-342

Chaber A-L (2018) The era of human-induced diseases. EcoHealth 15:8-11

Chipperfield JD, Benito BM, O'Hara RB, Telford RJ, Carlson CJ (2020) On the inadequacy of species distribution models for modelling the spread of SARS-CoV-2: response to Araújo and Naimi. EcoEvoRxiv. https://doi.org/10.32942/osfio/mr6pn

Chomel BB, Belotto A, Meslin F-X (2007) Wildlife, exotic pets, and emerging zoonoses. Emerg Infect Dis 13(1):6-11

Crowl TA, Crist TO, Parmenter RR, Belovsky G, Lugo AE (2008) The spread of invasive species and infectious disease as drivers of ecosystem change. Front Ecol Environ 6:238-246

Cui J, Li F, Shi ZL (2019) Origin and evolution of pathogenic coronaviruses. Nat Rev Microbiol 17(3):181-192

Cyranoski D (2020) The biggest mystery: what it will take to trace the coronavirus source. Nat News. https://doi.org/10.1038/ d41586-020-01541-z

da Silva Santos S, de Lucena RFP, de Lucena Soares HK, Dos Santos Soares VM, Sales NS, Mendonça LET (2019) Use of mammals in a semi-arid region of Brazil: an approach to the use value and data analysis for conservation. J Ethnobiol Ethnomed $15: 33-33$

Davies G (2002) Bushmeat and international development. Conserv Biol 16:587-589

De Sadeleer N, Godfroid J (2020) The story behind COVID-19: animal diseases at the crossroads of wildlife, livestock and human health. Eur J Risk Regul 11:210-227

Díaz de León-Martínez L, Sierra-de la Vega L, Palacios-Ramírez A, Rodriguez-Aguilar M, Flores-Ramírez R (2020) Critical review of social, environmental and health risk factors in the Mexican indigenous population and their capacity to respond to the COVID-19. Sci Total Environ 733:139357

Doğan, Ö; Korkmaz, EM; Budak, M; Çıplak, B; Başıbüyük, HH (2020) Witnessing evolution of sars-cov-2 through comparative phylogenomics: The proximate origin is Guangdong, not Wuhan. Preprints, 2020050332.https://doi.org/10.20944/preprints202005 0332v2

Domingo E, Perales C (2014) Virus evolution. Wiley, Chichester

Ejaz H, Alsrhani A, Zafar A, Javed H, Junaid K, Abdalla AE, Abosalif KOA, Ahmed Z, Younas S (2020) COVID-19 and comorbidities: deleterious impact on infected patients. J Infect Public Health S1876-0341(1820):30593-30594

Epp T, Waldner C (2012) Occupational health hazards in veterinary medicine: zoonoses and other biological hazards. Can Vet $\mathrm{J}$ 53:144-150

Epstein JH, Field HE, Luby S, Pulliam JRC, Daszak P (2006) Nipah virus: impact, origins, and causes of emergence. Curr Infect Dis Rep 8(1):59-65

Estrada-Peña A, Ostfeld RS, Peterson AT, Poulin R, de la Fuente J (2014) Effects of environmental change on zoonotic disease risk: an ecological primer. Trends Parasitol 30(4):205-214

Eubank S, Guclu H, Kumar VA, Marathe MV, Srinivasan A, Toroczkai Z, Wang N (2004) Modelling disease outbreaks in realistic urban social networks. Nature 429:180-184

Everard M, Johnston P, Santillo D, Staddon C (2020) The role of ecosystems in mitigation and management of Covid-19 and other zoonoses. Environ Sci Pol 111:7-17 
FAO (2013) World Livestock 2013—changing disease landscapes. Rome

Gao Z, Xu Y, Sun C, Wang X, Guo Y, Qiu S, Ma K (2020) A systematic review of asymptomatic infections with COVID-19. J Microbiol Immunol Infect. https://doi.org/10.1016/jjmii20200 5001

Geoghegan JL, Holmes EC (2017) Predicting virus emergence amid evolutionary noise. Open Biol 7(10):170189

Gonzalez J-P, Souris M, Valdivia-Granda W (2018) Global spread of hemorrhagic fever viruses: predicting pandemics. In: Clifton NJ (ed) hemorrhagic fever viruses, vol 1604. Springer, Berlin, pp 3-31

Guo Y, Wu Y, Wen B, Huang W, Ju K, Gao Y, Li S (2020) Floods in China, COVID-19, and climate change. Lancet Planet Health 4:e443-e444

Gupta A, Banerjee S, Das S (2020) Significance of geographical factors to the COVID-19 outbreak in India. Model Earth Syst Environ 6:2645-2653

Han LL, Popovici F, Alexander JP Jr, Laurentia V, Tengelsen LA, Cernescu C, Gary HE Jr, Ion-Nedelcu N, Campbell GL, Tsai TF (1999) Risk factors for West Nile virus infection and meningoencephalitis, Romania, 1996. J Infect Dis Lett 179:230-233

Harris M, Caldwell JM, Mordecai EA (2019) Climate drives spatial variation in Zika epidemics in Latin America. Proc R Soc B Biol Sci 286(1909):20191578

Hu B, Zeng L-P, Yang X-L, Ge X-Y, Zhang W, Li B, Xie J-Z, Shen X-R, Zhang Y-Z, Wang N, Luo D-S, Zheng X-S, Wang M-N, Daszak P, Wang L-F, Cui J, Shi Z-L (2017) Discovery of a rich gene pool of bat SARS-related coronaviruses provides new insights into the origin of SARS coronavirus. PLoS Pathog 13:e1006698-e1006698

Hubálek Z, Halouzka J (1999) West Nile fever-a reemerging mosquito-borne viral disease in Europe. Emerg Infect Dis 5:643

IPCC W (2013) Climate Change 2013: the physical science basis contribution of working Group I to the fifth assessment report of the intergovern-mental panel on climate change stocker. In: F T, Qin D, Plattner G-K, Tignor M, Allen SK, Boschung J, Nauels A, Xia Y, Bex V, Midgley PM (eds) Cambridge University Press, Cambridge, $\mathrm{p} 1535$

Islam MR, Hoque MN, Rahman MS, Alam ASMRU, Akther M, Puspo JA, Akter S, Sultana M, Crandall KA, Hossain MA (2020) Genome-wide analysis of SARS-CoV-2 virus strains circulating worldwide implicates heterogeneity. Sci Rep 10:14004

Jones BA, Grace D, Kock R, Alonso S, Rushton J, Said MY, McKeever D, Mutua F, Young J, McDermott J, Pfeiffer DU (2013) Zoonosis emergence linked to agricultural intensification and environmental change. Proc Natl Acad Sci USA 110:8399-8404

Kaur N, Singh R, Dar Z, Bijarnia RK, Dhingra N, Kaur T (2021) Genetic comparison among various coronavirus strains for the identification of potential vaccine targets of SARS-CoV2. Infect Genet Evol 89:104490

Keesing F, Belden LK, Daszak P, Dobson A, Harvell CD, Holt RD, Hudson P, Jolles A, Jones KE, Mitchell CE (2010) Impacts of biodiversity on the emergence and transmission of infectious diseases. Nature 468:647-652

Kondo H, Seo N, Yasuda T, Hasizume M, Koido Y, Ninomiya N, Yamamoto Y (2002) Post-flood-infectious diseases in Mozambique. Prehosp Disaster Med 17:126-133

Kong W-H, Li Y, Peng M-W, Kong D-G, Yang X-B, Wang L, Liu M-Q (2020) SARS-CoV-2 detection in patients with influenza-like illness. Nat Microbiol 5:675-678

Kumar A, Gupta PK, Srivastava A (2020) A review of modern technologies for tackling COVID-19 pandemic Diabetes. Metab Syndr Clin Res Rev 14:569-573

Kutz SJ, Jenkins EJ, Veitch AM, Ducrocq J, Polley L, Elkin B, Lair S (2009) The Arctic as a model for anticipating, preventing, and mitigating climate change impacts on host-parasite interactions. Vet Parasitol 163:217-228

Li X, Song Y, Wong G, Cui JJSCLS (2020) Bat origin of a new human coronavirus: there and back again. Sci China Life Sci 63:461-462

Ma Y, Zhao Y, Liu J, He X, Wang B, Fu S, Yan J, Niu J, Zhou J, Luo B (2020) Effects of temperature variation and humidity on the death of COVID-19 in Wuhan, China. Sci Total Environ 724:138226

Maurya AP, Chikhale RV, Pandey P (2020) Transmission of SARSCoV-2 in South Asian countries: molecular evolutionary model based phylogenetic and mutation analysis. Environ Sustain. https://doi.org/10.1007/s42398-020-00123-Z

Memon MS, Solangi S, Lakho S, Arain ZI, Naz F, Zaki M (2014) Morbidity and mortality of malaria during monsoon flood of 2011: South East Asia experience. Iran J Public Health 43:28-34

Morand S, Jittapalapong S, Suputtamongkol Y, Abdullah MT, Huan TB (2014) Infectious diseases and their outbreaks in AsiaPacific: biodiversity and its regulation loss matter. PLoS ONE 9(2):e90032-e90032

Mossoun A, Calvignac-Spencer S, Anoh AE, Pauly MS, Driscoll DA, Michel AO, Nazaire LG, Pfister S, Sabwe P, Thiesen U (2017) Bushmeat hunting and zoonotic transmission of simian T-Lymphotropic Virus 1 in tropical West and Central Africa. J Virol 91:e02479-e12416

Mukumbang FC, Ambe AN, Adebiyi BO (2020) Unspoken inequality: how COVID-19 has exacerbated existing vulnerabilities of asylum-seekers, refugees, and undocumented migrants in South Africa. Int J Equity Health 19:141

Nabi G, Siddique R, Khan S (2020) Detecting viral outbreaks in future using enhanced environmental surveillance. Environ Res 188:109731

Naguib MM, Verhagen JH, Samy A, Eriksson P, Fife M, Lundkvist $\AA$, Ellström P, Järhult JD (2019) Avian influenza viruses at the wild-domestic bird interface in Egypt. Infect Ecol Epidemiol 9:1575687

Nyakarahuka L, Ayebare S, Mosomtai G, Kankya C, Lutwama J, Mwiine FN, Skjerve E (2017) Ecological niche modeling for filoviruses: a risk map for Ebola and Marburg virus disease outbreaks in Uganda. PLoS Curr 9:ecurrents.outbreaks.07992a87522e079 91f07229c07997cb023270a023272af023271

Okaka FO, Odhiambo BDO (2018) Relationship between flooding and out break of infectious diseases in Kenya: a review of the literature. J Environ Public Health 2018:5452938-5452938

Oztig LI, Askin OE (2020) Human mobility and coronavirus disease 2019 (COVID-19): a negative binomial regression analysis. Public Health 185:364-367

Pachetti M, Marini B, Benedetti F, Giudici F, Mauro E, Storici P, Masciovecchio C, Angeletti S, Ciccozzi M, Gallo RC, Zella D, Ippodrino R (2020) Emerging SARS-CoV-2 mutation hot spots include a novel RNA-dependent-RNA polymerase variant. J Transl Med 18:179

Pan SL, Zhang S (2020) From fighting COVID-19 pandemic to tackling sustainable development goals: an opportunity for responsible information systems research. Int J Inf Manag 55:102196

Parkinson AJ, Evengard B, Semenza JC, Ogden N, Børresen ML, Berner J, Brubaker M, Sjöstedt A, Evander M, Hondula DM, Menne B, Pshenichnaya N, Gounder P, Larose T, Revich B, Hueffer K, Albihn A (2014) Climate change and infectious diseases in the Arctic: establishment of a circumpolar working group. Int J Circumpolar Health 73:25163-25163

Patel A (2020) Preventing COVID-19 amid public health and urban planning failures in slums of Indian Cities. World Med Health Pol 12:266-273

Paull SH, Horton DE, Ashfaq M, Rastogi D, Kramer LD, Diffenbaugh NS, Kilpatrick AM (2017) Drought and immunity determine the intensity of West Nile virus epidemics and climate change impacts. Proc R Soc B Biol Sci 284(1848):20162078 
Peterson AT, Bauer JT, Mills JN (2004) Ecologic and geographic distribution of filovirus disease. Emerg Infect Dis 10(1):40-47

Petrie B, Barden R, Kasprzyk-Hordern B (2015) A review on emerging contaminants in wastewaters and the environment: current knowledge, understudied areas and recommendations for future monitoring. Water Res 72:3-27

Phillips CA, Caldas A, Cleetus R, Dahl KA, Declet-Barreto J, Licker R, Merner LD, Ortiz-Partida JP, Phelan AL, Spanger-Siegfried E (2020) Compound climate risks in the COVID-19 pandemic. Nat Clim Change 10(7):586-588

Podile AR, Basu A (2020) Opportunities, challenges and directions in science and technology for tackling COVID-19. Trans Ind Nat Acad Eng 5:97-101

Prata DN, Rodrigues W, Bermejo PH (2020) Temperature significantly changes COVID-19 transmission in (sub)tropical cities of Brazil. Sci Total Environ 729:138862

Pujadas E, Chaudhry F, McBride R, Richter F, Zhao S, Wajnberg A, Nadkarni G, Glicksberg BS, Houldsworth J, Cordon-Cardo C (2020) SARS-CoV-2 viral load predicts COVID-19 mortality. Lancet Respir Med 8:e70

Revich B, Tokarevich N, Parkinson AJ (2012) Climate change and zoonotic infections in the Russian Arctic. Int J Circumpolar Health 71:18792-18792

Rocklöv J, Dubrow R (2020) Climate change: an enduring challenge for vector-borne disease prevention and control. Nat Immunol 21:479-483

Roy HE, Bacher S, Essl F, Adriaens T, Aldridge DC, Bishop JD, Blackburn TM, Branquart E, Brodie J, Carboneras C (2019) Developing a list of invasive alien species likely to threaten biodiversity and ecosystems in the European Union. Glob Chang Biol 25:1032-1048

Sajadi MM, Habibzadeh P, Vintzileos A, Shokouhi S, Miralles-Wilhelm F, Amoroso A (2020) Temperature and latitude analysis to predict potential spread and seasonality for COVID-19. SSRN 3550308. https://doi.org/10.2139/ssrn3550308

Salkeld DJ, Padgett KA, Jones JH (2013) A meta-analysis suggesting that the relationship between biodiversity and risk of zoonotic pathogen transmission is idiosyncratic. Ecol Lett 16(5):679-686

Sanchez-Lorenzo A, Vaquero-Martínez J, Calbó J, Wild M, Santurtún A, Lopez-Bustins J-A, Vaquero J-M, Folini D, Antón M (2020) Anomalous atmospheric circulation favored the spread of COVID-19 in Europe. medRxiv 2020.04.25.20079590. https:// doi.org/10.1101/2020.04.25.20079590

Sas-Rolfes Mt, Challender DWS, Hinsley A, Veríssimo D, MilnerGulland EJ (2019) Illegal wildlife trade: Scale, processes, and governance. Annu Rev Environ Resour 44:201-228

Scheffers BR, Oliveira BF, Lamb I, Edwards DP (2019) Global wildlife trade across the tree of life. Science 366:71-76

Schmeller DS, Courchamp F, Killeen G (2020) Biodiversity loss, emerging pathogens and human health risks. Biodivers Conserv 29:3095-3102

Schoukens H (2020) Rights of nature in the European Union: contemplating the operationalization of an eco-centric concept in an anthropocentric environment? In: Saramago A, Pereira JC (eds) Non-human nature in world politics: theory and practice. Springer International Publishing, Cham, pp 205-234

Shaman J, Day JF, Stieglitz M (2005) Drought-induced amplification and epidemic transmission of West Nile Virus in Southern Florida. J Med Entomol 42(2):134-141

Sharp PM, Hahn BH (2011) Origins of HIV and the AIDS pandemic. Cold Spring Harb Perspect Med 1:a006841

Shi P, Dong Y, Yan H, Zhao C, Li X, Liu W, He M, Tang S, Xi S (2020) Impact of temperature on the dynamics of the COVID-19 outbreak in China. Sci Total environ 728:138890-138890

Slingenbergh J, Gilbert M, Balogh Kd, Wint W (2004) Ecological sources of zoonotic diseases. Rev Sci Tech 23:467-484
Smit LAM, Heederik D (2017) Impacts of intensive livestock production on human health in densely populated regions. GeoHealth $1: 272-277$

Smith KM, Machalaba CC, Seifman R, Feferholtz Y, Karesh WB (2019) Infectious disease and economics: the case for considering multi-sectoral impacts. One Health 7:100080

Sobral MFF, Duarte GB, da Penha Sobral AIG, Marinho MLM, de Souza Melo A (2020) Association between climate variables and global transmission of SARS-CoV-2. Sci Total Environ 729:138997

Sutherst RW (2004) Global change and human vulnerability to vectorborne diseases. Clin Microbiol Rev 17:136-173

Suzán G, Marcé E, Giermakowski JT, Mills JN, Ceballos G, Ostfeld RS, Armién B, Pascale JM, Yates TL (2009) Experimental evidence for reduced rodent diversity causing increased hantavirus prevalence. PLoS ONE 4(5):e5461

Torgerson PR, Macpherson CNL (2011) The socioeconomic burden of parasitic zoonoses: global trends. Vet Parasitol 182:79-95

UNCCD and FAO (2020) Land degradation neutrality for water security and combatting drought, Bonn

UNEP (2016) UNEP frontiers 2016 report: emerging issues of environmental concern united nations environment programme, Nairobi

Urrutia-Pereira M, Mello-da-Silva CA, Solé D (2020) COVID-19 and air pollution: a dangerous association? Allergol Immunopathol 48:496-499

Van den Hurk AF, Ritchie SA, Mackenzie JS (2009) Ecology and geographical expansion of Japanese encephalitis virus. Annu Rev Entomol 54:17-35

Vargas-Berrones K, Bernal-Jácome L, Díaz de León-Martínez L, Flores-Ramírez R (2020) Emerging pollutants (EPs) in Latin América: a critical review of under-studied EPs, case of studynonylphenol. Sci Total Environ 726:138493

Waits A, Emelyanova A, Oksanen A, Abass K, Rautio A (2018) Human infectious diseases and the changing climate in the Arctic. Environ Int 121:703-713

Walsh KA, Jordan K, Clyne B, Rohde D, Drummond L, Byrne P, Ahern S, Carty PG, O'Brien KK, O'Murchu E, O'Neill M, Smith SM, Ryan M, Harrington P (2020) SARS-CoV-2 detection, viral load and infectivity over the course of an infection. J Infect 81:357-371

Wang L, Crameri G (2014) Emerging zoonotic viral diseases. Rev Sci Tech 33(2):569-581

Wang L-F, Anderson DE, Mackenzie JS, Merson MH (2020) From Hendra to Wuhan: what has been learned in responding to emerging zoonotic viruses. Lancet 395(10224):e33-e34

WHO (2009) Megacities and urban health report. Kobe, Japan

Wu F, Zhao S, Yu B, Chen Y-M, Wang W, Song Z-G, Hu Y, Tao Z-W, Tian J-H, Pei Y-Y (2020a) A new coronavirus associated with human respiratory disease in China. Nature 579:265-269

Wu Y, Jing W, Liu J, Ma Q, Yuan J, Wang Y, Du M, Liu M (2020b) Effects of temperature and humidity on the daily new cases and new deaths of COVID-19 in 166 countries. Sci Total Environ 729:139051

Wu A, Peng Y, Huang B, Ding X, Wang X, Niu P, Meng J, Zhu Z, Zhang Z, Wang J, Sheng J, Quan L, Xia Z, Tan W, Cheng G, Jiang $T$ (2020c) Genome composition and divergence of the novel coronavirus (2019-nCoV) originating in China. Cell Host Microbe 27:325-328

Wu X, Nethery RC, Sabath BM, Braun D, Dominici F (2020d) Exposure to air pollution and COVID-19 mortality in the United States: A nationwide cross-sectional study. medRxiv 20202004200520054502. https://doi.org/10.1101/2020040520 054502

Xiao K, Zhai J, Feng Y, Zhou N, Zhang X, Zou J-J, Li N, Guo Y, Li $X$, Shen X (2020) Isolation of SARS-CoV-2-related coronavirus from Malayan pangolins. Nature 583:286-289 
Yao Y, Pan J, Liu Z, Meng X, Wang W, Kan H, Wang W (2020) No Association of COVID-19 transmission with temperature or UV radiation in Chinese cities. Eur Respir J 55:2000517

Zachreson C, Fair KM, Cliff OM, Harding N, Piraveenan M, Prokopenko M (2018) Urbanization affects peak timing, prevalence, and bimodality of influenza pandemics in Australia: results of a census-calibrated model. Sci Adv 4:eaau5294

Zell R, Krumbholz A, Wutzler P (2008) Impact of global warming on viral diseases: what is the evidence? Curr Opin Biotechnol 19:652-660

Zhou P, Yang X-L, Wang X-G, Hu B, Zhang L, Zhang W, Si H-R, Zhu Y, Li B, Huang C-L (2020) A pneumonia outbreak associated with a new coronavirus of probable bat origin. Nature 579:270-273

Zhu N, Zhang D, Wang W, Li X, Yang B, Song J, Zhao X, Huang B, Shi W, Lu R (2020) A novel coronavirus from patients with pneumonia in China, 2019. N Engl J Med 382:727-733

Publisher's Note Springer Nature remains neutral with regard to jurisdictional claims in published maps and institutional affiliations. 